\title{
Rhetorical organizations of defense in primary care
}

Tony Warne Salford Center for Nursing, Midwifery and Collaborative Research, University of Salford, UK, Sue McAndrew School of Health Care, University of Leeds, UK, Martin King School of Health, Psychology and Social Care, Manchester Metropolitan University, UK and Karen Holland School of Nursing and Institute of Health and Social Care, University of Salford, UK

\begin{abstract}
The sustained movement towards a more primary health care led National Health Service in the UK has involved individuals and organizations developing more effective ways of working. This has resulted in changes to the structure and functioning of primary care organizations, the development of new workers and, in some instances, handing over work to other health and social care agencies. These changes have contributed to what for many staff is a turbulent organizational and practice environment. Data from a 3-year project, commissioned by the North West Development Agency, is used to explore how staff involved in these changes dealt with this turbulence; 350 staff working within 18 Primary Care Trusts participated in the study. A multi-methods approach was used which facilitated an iterative analysis and data collection process. Thematic analysis revealed a high degree of congruence between the perceptions of all staff groups with evidence of a generally well-articulated, but often rhetorical view of the organizational and professional factors involved in the changes experienced. This rhetoric was used by individuals as a defense mechanism in dealing with the turbulence of change. The article discusses how these defense mechanisms need to be recognized and understood by managers so that a more supportive organizational culture is developed.
\end{abstract}

Key words: defense mechanisms; organizational change; rhetoric

Received: April 2006; accepted: December 2006

\section{Introduction}

Current UK policy guidance locates primary care at the frontiers of health care modernization (Department of Health (DoH), 1997; 1998; 2000a; 2005; 2006). Achieving the new primary health and social care services envisaged in this rich policy rubric has generated a sustained movement towards finding more effective ways of working across traditional organizational boundaries (Godber et al., 1997; Audit Commission, 2004; DoH, 2005; 2006). New ways of working include embracing new workers, providing services in new ways, and even

Address for correspondence: Tony Warne, Professor in Mental Health Care, Salford Centre for Nursing, Midwifery and Collaborative Research, University of Salford, Allerton Building, Salford, Greater Manchester, M6 6PU, UK. Email: A.R.Warne@Salford.ac.uk 'giving up' some service provision to others (Lewis, 2004). Such changes to organizational structures and functions can often result in individuals and teams feeling disenfranchised, demotivated or inspired and positively challenged (Sibbald, 2000; Kernick and Scott, 2002; Ross and Corbett, 2005). This article explores the use of rhetoric as individual and organizational defense mechanisms in response to the changes occurring in primary care and within primary care organizations as these were experienced by staff. The concept of rhetoric has shifted over time from its original positive use as a form of persuasion to the more contemporary and dismissive usage of denigration. Often rhetoric, as a contemporary concept, is used to distinguish between empty words and action, or between true or accurate information and misinformation or 'spin'. Whilst these contemporary views are understandable developments in the use of language and political 
processes, ultimately rhetoric, as a concept is concerned with persuasion. Persuasion can be something directed at self and/or others. It is in this context that rhetoric is used in this article. Rhetorical analysis can involve an emphasis on argumentation, composition, persuasion and invention in the arrangement of talk and/or text (Simons, 1990). Here we are concerned with the way in which rhetoric is used as a way to articulate individual and shared meaning (Jackson, 1999; Perelman, 2003). This article aims, through this exploration, to provide managers with a better understanding of what individuals might be saying and what this might mean. Managers will be able to use this awareness and understanding to ensure supportive processes reflect an organizational culture that is about nurturing and respecting the individual during times of organizational turbulence and change.

\section{Context}

This article reports on one analytical outcome of the Shaping the Future (StF) study. This study was conducted between 2002-2005. It aimed to identify the evidence base for delivering integrated health and social care; and the skills and knowledge required to deliver this care, together with the current and future education and training needs of the North West of England primary health and social care work force (Warne et al., 2006). The StF study was split into seven different work packages. Each of these work packages explored an interrelated element of the project, for example, systematic review of the literature, exploring the views of service users, benchmarking examples of best practice. This article has its genesis in the work package aimed at gathering the perceptions, views and aspirations of the primary care work force, in particular those staff working in and for a Primary Care Trust (PCT).

Current primary health care is increasingly situated within a turbulent professional, organizational and practice environment characterized by many disjunctions and tensions in and between managerial, educational, political and professional discourses, theories and practices (Lewis, 2004; Ham, 2005; Ross and Corbett, 2005). Such turbulence will continue as the proposals for primary health and social care $(\mathrm{DoH}, 2005 ; 2006)$ are implemented.

Primary Health Care Research \& Development 2007; 8: 183-192
The wider StF study was interested in better understanding how individuals and their organizations dealt with this turbulence. It appeared that many participants found personal and organizational sanctuary in the articulation of a range of different rhetorical claims, which were being used as unconscious organizational defense mechanisms (Warne et al., 2006). These defense mechanisms enable the individual to accommodate the dissonance experienced between what is believed and what is experienced. For example, the rhetoric of team working was used by participants as an epistemological anchor to a wider collective discourse of rationality. Team working is widely accepted as the preferred model as it represents a more effective form of collaborative working. It can be argued there is a large evidence base to support such ontological beliefs (see eg, Clarke, 1978; Poulton and West, 1993; FTPH, 2000; Howarth et al., 2004). Indeed, we found data collected via an anonymous questionnaire that initially confirmed this known, albeit utopian world. However, data collected through interviews and workshops, in the form of rich descriptions of individual's lived experiences, pointed to a different reality. Analysis of these descriptions revealed that for many participants 'team working' appeared not to exist beyond the rational rhetoric symbolized by the ubiquitous hierarchical organizational chart. Yet this is not what was being explicitly stated. Participants were espousing an approach they believed they were part of, and which was seen as being preferable to other approaches, yet it was an approach that was not evident in practice. We suggest the use of defense mechanisms such as the articulation of the rhetoric (team working is good) was a strategy for personal and organizational survival in what for many participants, was a very chaotic and turbulent reality.

Individuals use rhetorical defenses as a way to both contain the 'good and bad' aspects of their organizational experience in order to better deal with the ever-present organizational turbulence (Boothe, 2001; Hamilton, 2004). Stripping away such defenses would be unproductive as it would lead to inner conflict creating fragmentation of self, which ultimately could lead to organizational fragmentation (Kanter, 1985). The use of rhetoric in this way is not new. Aristotle (1991) defined rhetoric as being concerned with: 'the detection of the persuasive aspects of each matter' (p. 70). The concern is not, however, about whether attempts 
at persuasion are successful or not, but what the talk or text draws from in constructing an attempt at persuasion (Hamilton, 2004). Foss et al. (1991) defines rhetoric as conscious and purposive symbolic action, and likewise, Black (1997) supports this in describing rhetorical activity as always being crafted and contrived, although he notes the difficulty there is in defining 'rhetoric'. However, Black as a rhetorician subscribes to the view that people perform discourse in everyday life, which provides a better fit to our suggestion of unconscious defense mechanisms being 'used'. Some caution still needs to be exercised in responding to this suggestion however. For example, as Holloway and Jefferson (2000) note, it is 'defended subjects' (in particular, those people who are participating as subjects in research) who use defense mechanisms to protect themselves against anxiety borne out of negative life experiences. In noting this cautionary caveat this article draws upon the various performances of four rhetorical defenses revealed by the participants in the analysis of two interrelated data sets.

\section{Methods}

The research design employed in this work package involved two iterative approaches: (1) a survey and (2) a series of semi-structured interviews. Both the survey and interviews involved participants who were representative of three different levels of the PCT organization: Macro (staff working at Board or sub-Board level); Meso (staff managing a department or professional group) and Micro (staff working in direct patient contact). A region wide survey was envisioned, but this proved impossible in terms of getting a statistically significant response rate. Only 100 useable questionnaires were returned representing only $5 \%$ of the potential sample. Although disappointing, we believe that data derived from this very small group increased in terms of internal validity when presented with data from other sources. Interestingly there was little difference noted in the analysis of the responses across all three groups.

It was an early multi-professional stakeholder workshop that provided the impetus to further develop and extend the data collection approaches from the proposed semi-structured interviews. In particular data was collected through four stakeholder workshops as well as some 35 individual and group interviews. The final numbers of participants involved in this work package were: Survey $n=100$; Interviews $n=51$; Workshops $n=182$, giving an overall participant sample of 333 working in 18 of the possible 44 PCTs that made up our sample. Of these, $10 \%$ represented the Macro level; $28 \%$ the Meso level and $72 \%$ the Micro level.

Ethical approval was gained from the North West Multi-Centre Research Ethics Committee (MREC) in April 2003 and locally from each of the clinical governance and research governance departments of the PCTs involved. Individual consent was obtained from all individuals participating in the study.

\section{Data analysis}

The survey data was analysed using a descriptive statistical approach aimed at providing a base line picture across eight data cluster groups: organizational roles, strategic working, tactical working, operational working interpersonal relationships, cultural integration, educational integration and best practice. Generally all the groups were strongly associated in terms of agreement with no significant differences being found. Although this was not a very useful outcome in itself, these shared accounts were characterized by overwhelmingly positive responses. This high level of positive responses possibly indicated how individuals were unconsciously seeking to achieve a sense of ontological security (Warne et al., 2002) during a period of major change. As we were later to discover, the view of the world illustrated in this survey data was very different to the world revealed in the second data set. However, individual and collective rhetorical communication of this sort can help create a sense of individual felt reality, reminiscent of Argyris and Schon's (1978) espoused theory/theory in use analysis of managerial action and organizational behaviour (Hamilton, 2004). The second phase of data analysis (of the interviews and workshops) was based upon making a comparative thematic analysis of what was being espoused (survey) and what was experienced in practice (interviews). This thematic analysis drew upon the eight cluster groups of the survey and the six emergent themes from the literature review.

\section{Findings: rhetoric in use}

The survey data revealed an 'idealized' world, whilst the interview and case study data provided

Primary Health Care Research \& Development 2007; 8: 183-192 
evidence of a different reality. Perelman (2003) argued that individuals, and the organizations they collectively form, are likely to construct their own adaptation of reality, however idealized this might be. Such realties are built upon knowledge that consists of various interpretations of phenomena that are themselves, part of the social and cultural context in which these occur (Stake, 1995; Frank, 2003; Kim, 2003). The data revealed a series of rhetorical justifications used by individuals in dealing with the felt experience of change to the organization of primary care and the PCT organization. It is these rhetorical justifications that enable individuals and groups to unconsciously recognize and respond to the link made between an often remote, yet widely known, context, and the immediate situation they find themselves in (Perelman, 2003; Hamilton, 2004). Jackson (1999) argues that rhetoric can both serve to provide an individual with a sense of community, and also allow observers of these communities to be able to differentiate between the hierarchical (and quantitative dimensions - how much, how often, how high) and the transcendental (and qualitative dimensions - how good, how grand, how noble). As an analytical tool this is clearly useful. For example we found individuals who appeared sincere in the description of their organization being effective in its communication processes, when to the outsider observer it was clear poor communication was being experienced. There were four types of rhetoric to emerge in terms of their use and focus amongst the participant group. These were the rational, technical, normative and fantasy.

\section{Rational rhetoric}

This is a rhetoric used by individuals in making sense of wider expectations and ideas, which collectively provide a discourse of rationality. As was noted above, team working is an example. Team working as a rational rhetoric not only has its origins in organizational and management literature (Handy, 1975; Senge, 1990; Dyer, 1995) but is reinforced in governmental policy guidance as being the preferred way of working (DoH, 1997; Onyett, 1999; FTPH, 2000; Howarth et al., 2004). As a conceptual basis for practice, the survey data revealed a high shared commitment to team working, and working interprofessionally. For example, many respondents agreeing that individuals keep each other informed about what they are doing, the problems they Primary Health Care Research \& Development 2007; 8: 183-192 experience and progress being made towards shared objectives. However, in the case studies, some participants appeared to provide a different view:

At times I feel we are still treated as the doctors' handmaiden by some of the GPs.

(Micro)

I would describe my team as being integrated, but the PCT is not, too many people work for themselves and not for the wider organisation, but justify this by saying they are responding to patients needs. I think that most people don't want to change things in case they lose their job, so it makes you more defensive when you're asked to work with different people or in a different way.

(Micro)

Whilst the first observation represents a long standing concern (Soni et al., 1989), the second observation reveals a new sense of individual vulnerability that perhaps transcends the immediate organizational working relationship. Yet these data were also set in a context of effective communication processes. Effective communication has been seen as one of the major indicators of effective team working (Slater, 2002) and with evidence suggesting that where teams do not communicate effectively, then service fragmentation is likely to occur (Nochajski, 2001; Howarth et al., 2004). The rationality implicit in this assertion was supported in the survey data. For example, $81 \%$ of the respondents agreed or strongly agreed that meetings were held across the PCT frequently enough to ensure effective communication. Somewhat paradoxically within the second data set however, it was noted that effective communication, vital in clinical practice (Deacon et al., 2006), often failed to be exercised in team working relationships:

People need to spend more time talking about how to talk to each other, we get taught how to talk to patients but not how to talk to each other.

(Micro)

Likewise, some individuals felt they did not always get the information they required from their organization. For example, an Audiologist noted: 
I found out what our PCT was planning for the next 12 months by reading a pamphlet I found in our local Pharmacy, up to that point I didn't know what was happening to our service.

(Micro)

It is clear that despite what was being said with regard to effective communication, the lived experience appeared very different. Often the use of rational rhetoric in this way overlapped with the individuals' use of technical rhetoric.

\section{Technical rhetoric}

These are used by individuals to describe the technical discourses in use that promote a particular approach to organizational processes. It is the technical process rather than the human element that is considered important. So perhaps paradoxically claims that Total Quality Management is an effective approach to bring about an improvement in the quality of care will be made but not where the social processes involved are acknowledged or recognized (Baker et al., 1996; Hosking and Haslam, 1997). For example, in the survey data, $65 \%$ of respondents agreed or strongly agreed that individuals within their PCT were open about their interests and expectations, and that in dealing with others', formal processes rather than covert agendas were used. Whereas, data from the case studies revealed a more pragmatic awareness of how organizational politics for example, could be experienced by individuals and teams, and on a wider level, the often rhetorical nature of organizational politics (Vigoda, 2000), was also revealed in the experience of participants:

People in our PCT have no idea whose in charge or what the corporate plans are.

(Meso)

I think we have a tick box approach to integration ... we invite representatives from social services to our meetings but its just because we have to, not because we want to.

(Micro)

We need more clarity about our decisionmaking processes, particularly joint decision making between different organisations.

(Meso)
Some respondents questioned whether, given the rapid pace of changes in primary health care, there was a formalized and shared understanding of what the services were aiming to achieve, for example a Health Visitor noted:

We have discussed what is now meant by 'public health practice' in our team, and we couldn't agree, most of our work is with individuals or maybe groups and rather than being at a community level ... I am not sure how we gain a better understanding of what is expected from us now.

(Micro)

There were also more positive examples of technical rhetoric's, for example:

The Assistant Practitioners are the way to achieve integrated care. We have started from the point of developing job descriptions and competencies in terms of what we think these new workers could do, and then we recruit them and train them up. Otherwise you just get a higher paid Nursing Assistant and nothing changes.

(Meso)

This data also brings into sharp relief two ends of the same technical rhetoric continuum, the adoption of a 'blank sheet of paper' perspective as opposed to a pre-determined 'replacement' or 'substitute’ approach (Warne and McAndrew, 2004).

\section{Normative rhetoric}

These are used by individuals to explain why unintended outcomes for a given range of inputs are the norm (Hofstede, 1983). Importantly, however, where the achievement of this is thought to rely on the ontological appeal of bringing about changes through winning the hearts and minds of individuals (Valle and Perrewe, 2000). An example of this might be the articulation of the notion that a supportive organizational culture will impact upon the individuals' response to adopting life long learning approaches to their professional and personal development. Data from the survey, suggested that $88 \%$ of respondents agreed or strongly agreed that individuals actively seek to learn from the experience and knowledge of others working in their PCT. This

Primary Health Care Research \& Development 2007; 8: 183-192 
was congruent with some of the case study participants experience.

I learnt a lot from the Midwives, they were good at showing you the whole patient journey, it taught me that to be a good Doctor, I'd need to make sure I knew more about the patients life, not just what brought them to the surgery.

(Meso)

However, many other respondents did not report similar experiences:

When I went out with the CPN, he wouldn't let me go in his car, he was dead funny about ... so I had to use my own and I kept getting lost driving around and around ... I hated being in the community, for me it was a waste of time.

(Micro)

In addition to the above, doubt is also raised within the survey data as to how much learning is undertaken through either formalized or informal approaches. For example, although $98 \%$ of the survey respondents agreed or strongly agreed that wherever possible, education and learning opportunities should be shared by different professions, of these only $12 \%$ had actually participated in any such activities. Perhaps this accounts for other survey data that revealed that only $52 \%$ of respondents agreed or strongly agreed that they felt they clearly understood the roles of staff from other professions working in their organization. The case study data also revealed the difficulties in achieving this understanding:

I think there are too many assumptions about different professional roles, even within the professions.

(Micro)

Given that patients should receive a seamless service (well that's the vision), it's strange that not many others in the PCT understand my role.

(Micro)

The pervasive influence of the normative rhetoric was also revealed:

Government targets force different organisations to come together, but people still have

Primary Health Care Research \& Development 2007; 8: 183-192 different ideas about what they should be doing, for example, in my PCT Ambulance staff and nursing staff have very different ideas about what unscheduled care involves and how we should be providing services even though we are allegedly both working for the same patients.

(Meso)

Life long learning was often cited as a way of addressing these issues. For example, $86 \%$ of survey respondents agreed or strongly agreed that life long learning should be a central feature in the development of the PCT and service improvement activities. However, data from the case studies again provided a mixed picture as to how this was being carried out in practice. For example, we often found very contrasting accounts of what life long learning involved:

Its all about life long learning and CPD and all that rubbish, but when it comes down to it the whole thing is very restrictive, you can't really do what you want to do, only what you are told you can do.

(Micro)

I think its hard to work in a service which is changing its function, there are so many changes right now ... and we are trying to get established in our roles, get to know the new staff and the service still has to run, patients still have to be seen, and CPD, if you're looking at priorities, is right at the bottom and is likely to stay there unless someone pushes me.

(Micro)

Additionally there also often appeared to be a lack of organizational commitment (Vigoda, 2000) in supporting these type of initiatives:

I have been offered lots of opportunities to meet with staff from social services, and I try and make sure all my staff get similar opportunities ... and although we have done this, for example District Nurses working with CAT [Community Alcohol Team] we haven't really carried on doing it on a regular basis due to a lack of money for backfilling ... I don't think my boss sees this as proper training ... but I keep trying.

(Meso) 


\section{Fantasy rhetoric}

These are used by individuals in providing explanations for the lived reality they find themselves in. This approach is rich in the identification of heroes and villains, emotions and attitudes, which make up the individuals social reality (Hofstede, 1983; Bowins, 2004). The importance of effective communication as recognized above needs careful consideration in terms of fantasy rhetoric. In this instance both the implicit and explicit messages take on personal meaning, which in turn will dictate the resultant behaviour (Boothe, 2001). For example:

We don't get told anything; we are just expected to get on with whatever new change is flavour of the moment.

(Micro)

Integrated health and social care is about the multiplicity of different agencies that all use different languages ... different languages are the reality of joint working, but make joint working more difficult.

(Meso)

We have to work with 4 other PCTs and 4 Acute Trusts, and you just feel lost and insignificant in the greater scheme of things ... I just keep my head down.

(Micro)

These data, although concerned with the difficulties in joint working, are equally representative of many of the participants' everyday working within their own teams and departments. Although many participants reported that they were able to attend lots of regular meetings, some of these (often those used to discuss organizational developments or changes) were viewed with suspicion. A typical example of this view was

Its like a game we all play, you go along and listen to what's being said and you know that anything you say will be ignored but everyone has to go so management can say staff have been consulted.

(Micro)

Many participants remained sceptical as to the purpose of some of the information communicated and how this was communicated. For example, one Occupational Therapist noted:

Our information systems are transparent, you can see right through them. We have a weekly communication letter, but its like a glorified births, deaths and marriages ... they [PCT Board Directors] do not tell us anything useful, like why some decision has been taken or whatever, if you ask them for this they say they don't know ... like as if you believe that.

(Micro)

The survey data suggested $65 \%$ of respondents agreed or strongly agreed that all groups in the PCT participated in being able to define problems or issues to be addressed. Participants in the case studies were less certain, and whilst some participation was reported, individuals often noted that this was experienced as being somewhat tokenistic (Witt et al., 2000), for example one Team Leader noted:

I think the only way we will ever get a real idea of what the strategic aims of the PCT are is when we have a two way process that genuinely involves people at the Board level and the workers. At the moment everything is presented as a fait accompli or maybe you get asked for possible solutions, but it feels like the decision has already been taken. It just makes people suspicious of what the PCT really wants to happen. So potential opportunities are missed because people feel threatened and don't believe what they're been told.

(Meso)

Ironically, many health care workers are drawn into health and social care because of the sense of personal security health care organizations afford them (Menzies Lyth, 1988; Gilmartin, 2000). Somewhat paradoxically, as these participants accounts show, organizational life can be full of insecurities, and individuals use defense mechanisms to protect themselves against the anxiety that the insecurity raises (Winnicott, 1989). We suggest that the four examples of rhetoric presented above are examples of defense mechanisms in use during a time of great organizational change in primary care. What these

Primary Health Care Research \& Development 2007; 8: 183-192 
experiences might also represent is the organizational unconscious that can make achieving cultural change in organizations so difficult (Allen and Kraft, 1982; Wayne and Stark, 2004).

\section{Discussion}

The management of organizational culture is increasingly seen as a necessary part of health care system reform (Scott et al., 2003). Reforms in the UK are predicated upon the notion that cultural as well as structural and functional organizational change is required to deliver the government's objectives (DoH, 2000b). This perspective of organizational culture, as an organizational attribute is predicated on the notion that culture can be manipulated (Handy, 1975; Allen and Kraft, 1982). In some situations this notion might be seen as attractive. It is clearly possible to 'manipulate' organizational culture for functional improvements, through for example, 're-engineering' the organization's values system (Kanter, 1985). An alternative perspective is that organizational culture defines the whole character and experience of organizational life (Hofstede, 1983), what the organization is (Scott et al., 2003). Here organizations are construed as cultures existing in and reproduced through the social interaction of its members (Hamilton, 2004). It is within the context of such social interactions that the rhetorical claims presented above can be revealed. Individuals utilize rhetorical claims based upon rational, technical, normative and fantasy rhetoric, as psychological defense mechanisms to maintain emotional homeostasis in times of overwhelming change (Bowins, 2004). The higher the level of anxiety experienced, the more defense mechanisms are employed to help maintain a sense of self (Yegdich, 1999). It has been argued that just as individuals use these defense mechanisms to deal with their own anxiety and reduce the impact of working in a turbulent environment (Bion, 1961; Clarke, 1999), managers also need to better understand these processes so that they can more effectively support their staff (Warne and McAndrew, 2006).

We argue that organizational turbulence needs to be contained and the rhetorical defenses that give the individual protection from the conflictridden realities of organizational life need to be openly acknowledged. Drawing on the work of
Winnicott (1989), 'containing' here refers to a process where individuals can be metaphorically 'held' allowing them to safely explore new ways of thinking, behaving and working with others. Interestingly, many staff thought the most beneficial training and development approaches they had experienced were those that involved staff taking time out from the everyday busyness of practice. Often these were team building exercises used to allow the multi-professional team to focus on an aspect of organizational life. We suggest this approach presents managers with the opportunity to engage in a psychoanalytically informed internal analysis (Hinshelwood, 1993) of their organizational culture such as the one described here. Investing in personal, professional and organizational development in this way is difficult. It needs to be regular and the time protected. However, we argue it would help ensure that managers learn to recognize, contain and more effectively harness the thoughts, feelings and vulnerabilities integral to the humanity of the organization, as these are reflected in rhetorical claims of individuals.

\section{Conclusion}

Primary and community health and social care organizations have experienced a sustained period of change. Further changes to the structure and functioning of these organizations are likely, and will result in turbulence within professional communities of practice and their related organizational environments. This article has explored how defense mechanisms, in the form of rhetorical claims, were used by individuals in dealing with what is often a very chaotic and messy reality. Individuals used rhetorical defenses as a way to both contain the 'good and bad' aspects of their organizational experience in order to better deal with the ever-present organizational turbulence. It has been argued that rhetoric can provide the manager with a psychoanalytically informed approach to gaining a better understanding of their organizational culture. Increased understanding of what is being said and what this might mean for individuals can be used to ensure supportive processes reflect an organizational culture that is about nurturing and respecting of the individual during times of organizational turbulence and change. 


\section{References}

Allen, F. and Kraft, C. 1982: The organisational unconscious: how to create the corporate culture you want and need. New Jersey: Prentice Hall.

Argyris, C. and Schon, D. 1978: Organisational learning: a theory of action perspective. Massachusetts: Addison Wesley.

Aristotle 1991: The art of the rhetoric. London: Penguin Classics.

Audit Commission. 2004: Transforming primary care. London: Audit Commission.

Black, E. 1997: Rhetoric's prospects: twenty-five years later. In Enos, T. and McNabb, R., editors, Making and unmaking the prospects for rhetoric. New Jersey: Lawrence Erblaum Associates.

Baker, J., Lattimer, P. and Matherson, L. 1996: Quality control and social processes: a case for acceptance sampling. Benchmarking: An International Journal 3, 51-67.

Bion, W. 1961: Theory of thinking. The International Journal of Psychoanalysis 43, 306-10.

Boothe, B. 2001: The rhetorical organisation of dream telling. Counselling and Psychotherapy Research 1,101-13.

Bowins, B. 2004: Psychological defense mechanisms: a new perspective. The American Journal of Psychoanalysis 64, 1-23.

Clarke M. 1978: Getting through the world. In Dingwall, R. and Mackintosh, J., editors, Readings in the sociology of nursing. Edinburgh: Churchill Livingstone.

Deacon, M., Warne, T. and McAndrew, S. 2006: Closeness, chaos, and crisis: the attractions of working in acute mental health care. Journal of Psychiatric and Mental Health Nursing 13, 750-57.

Department of Health (DoH). 1997: The new NHS: modern and dependable. London: The Stationary Office.

Department of Health (DoH). 1998: Working together. London: The Stationary Office.

Department of Health (DoH). 2000a: The NHS plan. London: The Stationary Office.

Department of Health (DoH). 2000b: Shifting the balance of power within the NHS: securing delivery. London: The Stationary Office.

Department of Health (DoH). 2005: Creating a patient-led NHS: delivering the NHS improvement plan. London: The Stationary Office.

Department of Health (DoH). 2006: Our health, our care, our say. London: The Stationary Office.

Dyer, W. 1995: Team building: current issues and new alternatives. Boston: Addison Wesley.

Forum on Team working in primary Healthcare (FTPH). 2000: Team working in primary health care: realising shared aims in patient care. London: Royal Pharmaceutical Society of Great Britain and The British Medical Association.

Foss, S., Foss, K. and Trapp, R. 1991: Contemporary perspectives on rhetoric. Illinois: Waveland Press.

Frank, D. 2003: After the new rhetoric. Quarterly Journal of Speech 89, 253-66.
Gilmartin, J. 2000: Psychodynamic resistance among student nurses: some observations in a human relations context. Journal of Advance Nursing 32, 1533-41.

Godber, E., Robinson, R. and Steiner, A. 1997: Economic evaluation and the shifting balance towards primary care: definitions, evidence and methodological issues. Health Economics 6, 275-94.

Ham, C. 2005: Primary care workforce awaits its rescue. Health Service Journal, September, 10-11.

Hamilton, P. 2004: Regeneration, rhetoric and the NHS: the case of the vital connection. The International Journal of Public Sector Management 17, 8-23.

Handy, C. 1975: Understanding organisations. London: Penguin.

Hinshelwood, R. 1993: The psychotherapists role in a large psychiatric institution. Psychoanalysis and Psychotherapy 2, 207-15.

Hofstede, G. 1983: The cultural relativity of organisational practice and theories. Journal of International Business Studies 14, 75-89.

Holloway, W. and Jefferson, T. 2000: Doing qualitative research differently. London: Sage.

Hosking, D. and Haslam, P. 1997: Managing to relate: organizing as a social process. Career Development International 2, 85-89.

Howarth, M., Grant, M. and Holland, K. 2004: Shaping the future for primary education \& training project: a systematic review of the literature. Salford: University of Salford.

Jackson, B. 1999: The goose that laid the golden egg?: A rhetorical critique of Stephen Covey and the effectiveness movement. Journal of Management Studies 36, 354-77.

Kanter, R. 1985: Managing the human side of change. Management Review 5, 56-59.

Kernick, D. and Scott, A. 2002: Economic approaches to doctor/nurse skill mix: problems, pitfalls and practice solutions. The British Journal of General Practice 52, 42-46.

Kim, S. 2003: Research paradigms in organisational learning and performance: competing modes of enquiry. Journal of Information Technology Learning and Performance 21, 9-18.

Lewis, R. 2004: Practice led commissioning: harnessing the power of the primary care front line. London: Kings Fund.

Menzies Lyth, I. 1988: The functioning of social systems as a defense against anxiety. In Menzies Lyth I., editor, Containing anxiety in institutions: selected essays. London: Free Association Books.

Nochajski, S. 2001: Collaboration between team members in inclusive educational settings. Interprofessional Collaboration in Occupational Therapy 15,101-12.

Onyett S. 1999: Community mental health team working as a socially valued enterprise. Journal of Mental Health 8, 245-51.

Perelman, C. 2003: First philosophies and regressive philosophy. Philosophy and Rhetoric 36, 189-206.

Poulton, B. and West, M. 1993: Effective multidisciplinary teamwork in primary health care. Journal of Advanced Nursing 18, 918-25.

Ross, F. and Corbett, K. 2005: Primary care nursing: education for changing roles and boundaries. Education for Primary Care 16, 246-55.

Primary Health Care Research \& Development 2007; 8: 183-192 
Scott., Mannion R., Marshall M. and Davies H. 2003: Does organisational culture influence health care performance? A review of the evidence. Journal of Health Services Research and Policy 8: 105-117.

Senge, P. 1990: The Fifth Discipline: the art and practice of the learning organisation. New York: Doubleday.

Sibbald, B. 2000: Interdisciplinary working in British primary care teams: a threat to cost effectiveness of care. Critical Public Health 10, 439-51.

Simons, H. 1990: The rhetoric of inquiry as an intellectual movement. In Simons, H., editor, The rhetorical turn: invention and persuasion in the conduct of inquiry. Chicago: University of Chicago Press.

Slater, P. 2002: Training for no secrets: a strategic initiative. Social Work Education 21, 437-48.

Soni, S., Steers L., Warne T. and Sang, W. 1989: Multi-disciplinary teams and line management: practical problems and areas of conflict in clinical psychiatry. Royal College of Psychiatrists Psychiatric Bulletin 13, 657-61.

Stake, R. 1995: The art of case study research. London: Sage publications.

Valle, M. and Perrewe, P. 2000: Do politics perceptions relate to political behaviours? Tests of an implicit assumption and expanded model. Human Relations 53, 359-86.

Vigoda, E. 2000: Organisational politics, job attitudes and work outcomes: exploration and implications for the public sector. Journal of Vocational Behaviour 57, 326-47.
Warne, T. and McAndrew, S. 2004: The mental health assistant practitioner: an oxymoron. Journal of Psychiatric and Mental Health Nursing 11, 179-84.

Warne, T. and McAndrew, S. 2006: Splitting the difference: the heroes and villains of mental health policy and nursing practice. Issues in Mental Health Nursing 27, 1001-13.

Warne T. and Stark S. 2004: Service users, metaphors and team working in mental health. Journal of Psychiatric and Mental Health Nursing 11, 654-61.

Warne, T., Skidmore, D. and McAndrew, S. 2002: The NHS plan: a policy-practice tension, phoenixtn.net/evora/papers Original/presentation

Warne, T., King, M., Street, C. and McAlonan, C. 2006: Finding the evidence for education and training to deliver integrated health and social care: the primary care workforce. Shaping the Future for Primary Care Education and Training Project, University of Salford, Salford.

Winnicott, D. 1989: Holding and interpretation: fragments of an analysis. New York: Grove Press.

Witt, L., Andrews, M. and Kacmar, K. 2000: The role of participation in decision making in the organizational politics - job satisfaction relationship. Human Relations 53, 341-58.

Yegdich, T. 1999: Lost in the crucible of supportive clinical supervision: supervision is not therapy. Journal of Advanced Nursing 29, 1265-75. 